\title{
Water-soluble fractions of composts for the photodegradation of organic pollutants in solar light
}

\author{
Amina Amine-Khodja • Claire Richard . \\ Bernadette Lavédrine • Ghislain Guyot • \\ Olga Trubetskaya $\cdot$ Oleg Trubetskoj
}

Published online: 1 August 2006

(C) Springer-Verlag 2006

\section{Environ Chem Lett (2006) 4:173-177}

Unfortunately, the name of the first author was published with errors. The correct name is given here: Amina AmineKhodja

The online version of the original article can be found at http://dx.doi.org/10.1007/s10311-005-0028-8

A. Amine-Khodja $\cdot$ C. Richard $(\bowtie) \cdot$ B. Lavédrine $\cdot$ G. Guyot Laboratoire de Photochimie Moléculaire et Macromoléculaire, UMR no. 6505, CNRS-Université Blaise Pascal,

63177, Aubière Cedex, France

e-mail: claire.richard@univ-bpclermont.fr

Tel.: +33-4-73-40-71-42

Fax: +33-4-73-40-77-00

O. Trubetskaya

Branch of Shemyakin and Ovchinnikov Institute of Bioorganic Chemistry, Russian Academy of Sciences,

142290 Pushchino, Moscow, Russia

O. Trubetskoj

Institute of Fundamental Problems in Biology,

Russian Academy of Sciences,

142290 Pushchino, Moscow, Russia 